\title{
Treating Drug Abuse and Addiction in the Criminal Justice System: Improving Public Health and Safety
}

\author{
Redonna K. Chandler, $\mathrm{PhD}^{1}$, Bennett W. Fletcher, $\mathrm{PhD}^{1}$, and Nora D. Volkow, $\mathrm{MD}^{2}$ \\ ${ }^{1}$ Services Research Branch, National Institute on Drug Abuse, Bethesda, Maryland ${ }^{2}$ National Institute on \\ Drug Abuse, Bethesda, Maryland
}

\begin{abstract}
Despite increasing evidence that addiction is a treatable disease of the brain, most individuals do not receive treatment. Involvement in the criminal justice system often results from illegal drug-seeking behavior and participation in illegal activities that reflect, in part, disrupted behavior ensuing from brain changes triggered by repeated drug use. Treating drug-involved offenders provides a unique opportunity to decrease substance abuse and reduce associated criminal behavior. Emerging neuroscience has the potential to transform traditional sanction-oriented public safety approaches by providing new therapeutic strategies against addiction that could be used in the criminal justice system. We summarize relevant neuroscientific findings and evidence-based principles of addiction treatment that, if implemented in the criminal justice system, could help improve public heath and reduce criminal behavior.
\end{abstract}

The past 20 years have seen significant increases in the numbers of individuals incarcerated or under other forms of criminal justice supervision in the United States. These numbers are staggering - approximately 7.1 million adults in the United States are under some form of criminal justice supervision. ${ }^{1}$ The large increase in the criminal justice population reflects in part tougher laws and penalties for drug offenses. ${ }^{2}$ An estimated one-half of all prisoners (including some sentenced for other than drug offenses) meet the criteria for diagnosis of drug abuse or dependence (Table 1). ${ }^{3,4}$

During the past 20 years, fundamental advances in the neurobiology of addiction have been made. Molecular and imaging studies have revealed addiction as a brain disorder with a strong genetic component, and this has galvanized research on new pharmacological treatments.

However, a large disconnect remains between addiction research and the treatment of addiction

Corresponding Author: Nora D. Volkow, MD, National Institute on Drug Abuse, 6001 Executive Blvd, Room 5274, Bethesda, MD 20892 (E-mail: nvolkow@nida.nih.gov).

Author Contributions: Study concept and design: Chandler, Fletcher, Volkow.

Financial Disclosures: None reported.

Publisher's Disclaimer: Disclaimer: The statements in this article are those of the authors and not necessarily those of the National Institute on Drug Abuse.

Additional Contributions: We thank Faye S. Taxman, PhD, and Matthew Perdoni, MS, both of George Mason University, for data on physical/medical, mental health, and substance use services (Table 2) from the NIDA National Criminal Justice Drug Abuse Treatment Studies (CJ-DATS) National Criminal Justice Treatment Practices Survey. Neither of these individuals received compensation for their contributions.

Analysis and interpretation of data: Fletcher.

Drafting of the manuscript: Chandler, Fletcher.

Critical revision of the manuscript for important intellectual content: Chandler, Fletcher, Volkow.

Administrative, technical, or material support: Chandler, Fletcher, Volkow. 
in general, particularly within the criminal justice system. This is evidenced in that most prisoners $(80 \%-85 \%)$ who could benefit from drug abuse treatment do not receive it. ${ }^{3,4}$ In addition, drug-using offenders are at high risk for infectious diseases such as human immunodeficiency virus (HIV) and hepatitis $\mathrm{C}^{5}$ and frequently have co-morbid psychiatric disorders, ${ }^{6,7}$ which further highlights the dire treatment needs of this population.

Not treating a drug-abusing offender is a missed opportunity to simultaneously improve both public health and safety. Integrating treatment into the criminal justice system would provide treatment to individuals who otherwise would not receive it, improving their medical outcomes and decreasing their rates of reincarceration. ${ }^{8}$

\section{Recidivism in the Drug-Abusing Offender}

The inadequacy of incarceration by itself in addressing drug abuse or addiction is evident in the statistics. A review of recidivism in 15 states found that one-quarter of individuals released returned to prison within 3 years for technical violations that included, among other things, testing positive for drug use. ${ }^{9}$ Illicit drugs are used in jails and prisons despite their highly structured, controlled environments, ${ }^{10}$ but even enforced abstinence can mislead criminal justice professionals as well as addicted persons to underestimate the vulnerability to relapse postincarceration. On release from prison or jail, addicted persons will experience challenges to their sobriety through multiple stressors that increase their risk of relapsing to drug use. These include the stigma associated with being labeled an ex-offender, the need for housing and legitimate employment, stresses in re-unifying with family, and multiple requirements for criminal justice supervision. 11,12

Returning to neighborhoods associated with preincarceration drug use places the addicted individual in an environment rich in drug cues. As discussed below, these conditioned cues automatically activate the reward/motivational neurocircuitry and can trigger an intense desire to consume drugs (craving). ${ }^{13}$ The molecular and neurobiological adaptations resulting from chronic drug use persist for months after drug discontinuation, ${ }^{14}$ and evidence exists that compulsive seeking of drugs when addicted individuals are reexposed to drug cues progressively increases after drug withdrawal. ${ }^{15}$ This could explain why many drug-addicted individuals rapidly return to drug use following long periods of abstinence during incarceration and highlights the need for ongoing treatment following release.

\section{Drug Abuse Treatment Effectiveness in the Criminal Justice System}

Research over the last 2 decades has consistently reported the beneficial effects of treatment for the drug abuser in the criminal justice system. ${ }^{16,17}$ These interventions include therapeutic alternatives to incarceration, treatment merged with judicial oversight in drug courts, prisonand jail-based treatments, and reentry programs intended to help offenders transition from incarceration back into the community. 8,18 Through monitoring, supervision, and threat of legal sanctions, the justice system can provide leverage to encourage drug abusers to enter and remain in treatment.

Behavioral treatments are the most commonly used interventions for addressing substance use disorders. Evidence-based behavioral interventions include cognitive therapies that teach coping and decision-making skills, contingency management therapies that reinforce behavioral changes associated with abstinence, and motivational therapies that enhance the motivation to participate in treatment and in non-drug-related activities. ${ }^{19,20}$ Many residential treatment programs rely on the creation of a "therapeutic community" based on a social learning model. ${ }^{21}$ Medications such as methadone, buprenorphine, and naltrexone are beneficial for the treatment of heroin addiction and naltrexone and topiramate for the treatment of alcoholism. 
22-24 Self-help programs such as Alcoholics Anonymous or SMART Recovery can be valuable adjuncts to formal drug treatment. ${ }^{25}$

Research has consistently shown that community-based drug abuse treatment can reduce drug use and drug-related criminal behavior. ${ }^{26} \mathrm{~A}$ meta-analysis of 78 comparison-group community-based drug treatment studies found treatment to be up to 1.8 times better in reducing drug use than the usual alternatives. ${ }^{20}$ In a meta-analysis of 66 incarceration-based treatment evaluations, therapeutic community and counseling approaches were respectively 1.4 and 1.5 times more likely to reduce reoffending. ${ }^{27}$ Drug courts combine judicial supervision with drug treatment as an alternative to incarceration; their graduates have rearrest rates about half those of matched comparison samples and much lower than those of drug court dropouts. ${ }^{28}$ Individuals who participated in prison-based treatment followed by a communitybased program postincarceration were 7 times more likely to be drug free and 3 times less likely to be arrested for criminal behavior than those not receiving treatment. 29,30

The benefits of medications for drug treatment were shown in a recent randomized trial in which heroin-dependent inmates began methadone treatment in prison prior to release and continued in the community postrelease. At 1-, 3-, and 6-month follow-up, patients who received methadone plus counseling were significantly less likely to use heroin or engage in criminal activity than those who received only counseling. ${ }^{31-33}$ The potential exists for immediate adoption of methadone maintenance for incarcerated persons with opioid addictions, but most prison systems have not been receptive to this approach. ${ }^{34}$

Economic analyses highlight the cost-effectiveness of treating drug-involved offenders. 35 On average, in- carceration in the United States costs approximately $\$ 22000$ per month, 36 and there is little evidence that this strategy reduces drug use or drug-related re-incarceration rates for nonviolent drug offenders. By contrast, the average cost of methadone is $\$ 4000$ per month, 37 and treatment with methadone has demonstrated effectiveness in reducing drug use and criminal activity following release. ${ }^{31}$ Alternatives to incarceration can also defray job productivity losses and the separation from family and social support systems.

The cost of integrating volunteer-led self-help organizations such as Alcoholics Anonymous and Narcotics Anonymous into criminal justice settings is nominal and could provide support to the recovery efforts of addicted persons in the criminal justice system. One dollar spent on drug courts is estimated to save approximately $\$ 4$ in avoided costs of incarceration and health care, 38 and prison-based treatment saves between $\$ 2$ to $\$ 6 .{ }^{39}$ These economic benefits in part reflect reductions in criminal behavior. ${ }^{40,41}$

\section{Access to Treatment}

Drug education - not drug treatment - is the most common service provided to prisoners with drug abuse or addiction problems. ${ }^{4,42}$ More than one-quarter of state inmates and 1 in 5 federal inmates meeting abuse/dependence criteria participate in self-help groups such as Alcoholics Anonymous while in prison. ${ }^{4}$ However, though treatment during and after incarceration has been shown to significantly reduce drug use and drug-related crime, less than $20 \%$ of inmates with drug abuse or dependence receive formal treatment (Table 1). ${ }^{3,4}$

In a recent survey of correctional programs and organizations across the United States, ${ }^{42}$ most correctional agencies reported providing sometype of drug abuse treatment services;however, the median percentage of offenders who had access to those services at any given time was low, usually less than $10 \%$ (Table 2). ${ }^{42}$ Even if a correctional institution does provide treatment, the continuity of treatment postincarceration, which is essential to recovery, ${ }^{16}$ is often lacking when the drug-involved offender transitions from incarceration to community 
supervision. ${ }^{43}$ Failure to receive treatment on release increases the risk not only of relapse but also of mortality from drug overdose and other causes. ${ }^{44}$

Infectious diseases such as HIV and hepatitis $\mathrm{C}$ are associated with illicit drug use and occur at higher rates in correctional populations than in the general population, ${ }^{5}$ but treatment for these conditions appears to fall short of need. ${ }^{45,46}$ It is feasible to implement screening and treatment in correctional settings for $\mathrm{HIV}^{47,48}$ and hepatitis $\mathrm{C}$. 49,50 Continuity of treatment for released offenders with infectious disease is crucial not only for the individual's health 51,52 but also for the health of the community. ${ }^{45,53}$

There are many barriers to treatment for the drug-involved offender, including lack of the resources, infrastructure, and treatment staff (including physicians knowledgeable about addiction medicine) required to meet the drug treatment needs of individuals under their supervision. Addiction remains a stigmatized disease not often regarded by the criminal justice system as a medical condition; as a consequence, treatment is not constitutionally guaranteed as is the treatment of other medical conditions.

\section{Neurobiology of Addiction}

Addiction is a chronic brain disease for which genetic factors are believed to contribute $40 \%$ to $60 \%$ of the vulnerability. ${ }^{54}$ Repeated drug exposure in individuals who are vulnerable (because of genetics, or developmental or environmental factors) trigger neuroadaptations in the brain that result in the compulsive drug use and loss of control over drug-related behaviors that characterizes addiction. Molecular and neuroimaging studies have helped illuminate how genes may affect vulnerability to addiction and how repeated use of addictive drugs causes long-lasting disruptions to the structure and function of the brain. ${ }^{55}$ Among the genes identified to contribute to the vulnerability for addiction are those that participate in the neuroplastic changes associated with learning. ${ }^{56}$ Imaging studies have identified multiple brain circuits that are disrupted in addicted persons ${ }^{57}$; these include circuits involved in reward and motivation, learning and memory, cognitive control, mood, and interoception (awareness of physiological body signals) (Figure). Disruption of these circuits impairs the addicted person's ability to inhibit intentional actions or to control strong emotions and desires and also increases the likelihood that the individual will have difficulties making adaptive decisions. 60,61

Addiction also decreases sensitivity in the reward and the motivational circuits, which modulate response to positive as well as negative reinforcers. Practically, this suggests that an addicted individual may experience less motivation to pursue activities likely to result in beneficial outcomes and to avoid those that could result in punishment. One can also predict that dysfunction in this neurocircuitry would reduce an addicted person's motivation to abstain from drug use because alternative reinforcers (natural stimuli) are comparatively weaker and negative consequences (eg, incarceration) are less salient. ${ }^{62}$

In parallel, the repeated use of drugs leads to the formation of new linked memories that condition the addicted individual to expect pleasurable responses-not only when exposed to a drug but also when exposed to stimuli associated with the drug. These stimuli trigger automatic responses that frequently drive relapse, even in individuals motivated to stop taking drugs. ${ }^{63}$ The enhanced sensitivity to drugs as rewards and the conditioning to associated drug cues increase the interoceptive awareness of discomfort (anxiety and tension) that occurs when the individual is exposed to drug cues and increase the desire to consume the drug. 64 Additionally, repeated drug use also affects brain regions implicated in mood and anxiety, which could explain the high rate of addiction comorbid with dysphoria, depression, or both and the vulnerability of the addicted person to relapse when exposed to social stressors. 65,66 
Impairment of the neural substrates affected by addiction - particularly those concerned with behavioral inhibition, control of emotions and desires, and decision-making-increase the likelihood that addicted individuals will make choices that appear impulsive. 67,68 This idea is supported by research in the emerging area of behavioral economics, which has found that addicted individuals differ from those who do not use drugs in how they make decisions.

Addicted individuals tend to have higher levels of temporal discounting than those who do not use drugs; ie, they tend to choose immediate, smaller rewards over future, larger rewards. 69 High temporal discounting is also associated with impulsivity - the inability to delay immediate gratification and to recognize the potential for negative consequences. ${ }^{70}$

Many of the neurobiological changes associated with repeated drug use persist for long periods after drug discontinuation. ${ }^{71}$ This helps explain why addicted individuals who have ceased drug use are at high risk of relapse and provides neurobiological support for the recognition of addiction as a chronic relapsing disease. 72

What are the implications of neuroscience research for how society and clinicians might regard the addicted offender? There are at least 3 implications for how this emerging knowledge about the neurologic basis of addictive behavior is important.

First, of most importance, neuroscience's uncovering of new molecular targets implicated in the responses to drugs and of new knowledge on the function of the human brain provides new targets for medication development and behavioral interventions in addiction. Although many of the neurobiological changes associated with repeated drug use persist for long periods after drug discontinuation, ${ }^{71}$ research suggests that the impaired brain can regain some of the functions damaged by use of illicit drugs over time. ${ }^{73}$

\section{Box. NIDA Principles of Drug Abuse Treatment for Criminal Justice Populations}

Drug addiction is a chronic brain disease that affects behavior

Recovery from drug addiction requires effective treatment, followed by continued care

Duration of treatment should be sufficiently long to produce stable behavioral changes

Assessment is the first step in treatment

Tailoring services to fit the needs of the individual is an important part of effective drug abuse treatment for criminal justice populations

Drug use during treatment should be carefully monitored

Treatment should target factors associated with criminal behavior

Criminal justice supervision should incorporate treatment planning for drug-abusing offenders, and treatment providers should be aware of correctional supervision requirements

Continuity of care is essential for drug abusers reentering the community

A balance of rewards and sanctions encourages prosocial behavior and treatment participation

Offenders with co-occurring drug abuse and mental health problems often require an integrated treatment approach

Medications are an important part of treatment for many drug-abusing offenders 
Treatment planning for drug-abusing offenders living in or reentering the community should include strategies to prevent and treat serious, chronic medical conditions such as human immunodeficiency virus/AIDS, hepatitis B and C, and tuberculosis

NIDA indicates National Institute on Drug Abuse. Principles adapted from Fletcher and Chandler. 75

Second, neuroscience establishes a biological framework for understanding aspects of addictive behavior that otherwise seem to defy rational explanation. In the absence of known biological determinants, these behaviors often have been attributed to "moral weakness."74 Identifying the neurologic factors underlying addictive behavior can place these moral arguments into a more reasoned context. Addiction does not absolve one of responsibility for use of illicit drugs or for criminal behavior, but understanding how addictive drugs affect behavior through brain mechanisms can inform decisions to provide treatment to addicted individuals. For example, mandated treatment may be useful for drug-involved offenders who would otherwise not engage in the treatment process or make progress toward recovery. The persistence of neurologic deficits provides support for the recognition of addiction as a chronic disease and highlights the need for the same continuity of care so important in treatment of other chronic diseases (eg, asthma, hypertension). ${ }^{72}$ It also suggests that agonist medications such as methadone are important treatments for addiction, even for individuals who have been under enforced abstinence during incarceration.

Third, neuroscience may help addicted individuals to better understand their own addiction. Such individuals may become frustrated when their efforts to control their own drug use are unsuccessful, and even with treatment many become frustrated with what is often a slow and tenuous recovery process. The neurobiology of the brain can help the addicted individual put this disease into a more understandable context and thereby facilitate effective treatment. Little research has been conducted in the field of addiction on whether knowing more about the substance use disorder is useful in helping to sustain recovery, and more research is needed. However, the concept of the "expert patient" who serves as his or her own best health advocate in a recovery management paradigm has been promoted for chronic disorders. As with these other illnesses, addiction must be managed by the individual over time to sustain recovery.

\section{Principles of Drug Abuse Treatment for Offenders}

Principles of Drug Abuse Treatment for Criminal Justice Populations, 75 published by the National Institute on Drug Abuse, synthesizes research on drug abuse treatment for drug abusers in the criminal justice system. It is intended as a resource for criminal justice professionals and the treatment community working with drug abusers involved with the system. The publication summarizes 20 years of research to provide guidance on evidencebased practices and identifies general principles on how to effectively address the drug abuse problems of populations involved with the criminal justice system (Box). ${ }^{75}$

\section{Implementing the Principles}

Effective interventions depend on a coordinated response between criminal justice agencies, drug abuse treatment providers, mental health and physical health care organizations, and social service agencies. Each type of criminal justice agency (eg, jail, drug court, probation, prison) has its own role in sanctioning and supervision and lends itself to specific intervention opportunities. Table 3 provides a simplified overview of the criminal justice system and identifies the points at which intervention is possible.

Effective integration of drug treatment interventions into criminal justice settings requires matching the intervention to the organization. For example, since jail stays are usually brief, the interventions best suited to jails may be screening for drug and alcohol abuse, other mental 
illnesses, and medical conditions (eg, HIV, hepatitis B or C), with referral to community-based treatment providers. Implementing these principles throughout the criminal justice and drug abuse treatment systems also requires that these systems work together to address the addicted individual's drug use, comorbid mental disorders and medical conditions, if present, and criminal behavior. Treatment professionals should understand the criminal justice process and the supervision requirements of their patients. In addition to addressing drug use behaviors, treatment outcomes improve when antisocial and criminal behaviors are targets of clinical intervention. ${ }^{76}$ Criminal justice professionals must develop an understanding of addictionsigns and symptoms, treatment, and relapse—and their role in facilitating recovery.

\section{Substance Abuse Treatment Research in Criminal Justice Settings}

Prison environments are inherently coercive, ${ }^{77}$ and special safeguards have been developed to ensure that prisoners can choose freely whether to participate in biomedical research without fear of consequence. Beyond mere equipoise, clinical trials must be designed so the research is of benefit to the prisoner participant regardless of the assigned study group. Within these constraints, it is important to conduct research to help improve substance abuse treatment and to assist in the successful transition of the substance abuser to the community. To facilitate research in this area, the National Institute on Drug Abuse created the Criminal Justice Drug Abuse Treatment Studies research cooperative, ${ }^{78}$ a network of correctional agencies linked with treatment research centers and community treatment programs.

Opiate agonist medications used for the treatment of heroin addiction such as methadone and buprenorphine are underused in correctional populations. Naltrexone, an opiate antagonist, was developed to treat heroin addiction but also has been approved for treating alcoholism. Naltrexone is likely to be more acceptable in the criminal justice setting than agonist medications. However, the poor compliance with naltrexone has limited its use in the treatment of heroin addiction. The recent development of a long-lasting depot formulation for naltrexone 79,80 obviates this limitation, and a multisite clinical trial (NCT00781898) is currently evaluating its effectiveness in heroin-addicted probationers. Another area of research intended to reduce relapse in addicted offenders is the development of vaccines against cocaine, methamphetamine, or heroin.

Several avenues currently exist for providing drug abuse treatment as an alternative to incarceration. Drug courts were intended to provide a bridge between drug treatment and adjudication; from the first drug court established in Miami in 1989, drug courts have increased in number to nearly 2000 today. States such as Arizona, California, and New York have created treatment alternatives to incarceration for first-time drug offenders, juvenile offenders, and others. Many states are coming under political pressure to reduce the costs associated with incarceration by diverting nonviolent drug offenders to treatment.

\section{Conclusions}

Punishment alone is a futile and ineffective response to drug abuse, ${ }^{2}$ failing as a public safety intervention for offenders whose criminal behavior is directly related to drug use. ${ }^{81}$ Addiction is a chronic brain disease with a strong genetic component that in most instances requires treatment. The increase in the number of drug-abusing offenders highlights the urgency to institute treatments for populations involved in the criminal justice system. It also provides a unique opportunity to intervene for individuals who would otherwise not seek treatment.

The challenge of delivering treatment in a criminal setting requires the cooperation and coordination of 2 disparate cultures: the criminal justice system organized to punish the offender and protect society and the drug abuse treatment systems organized to help the addicted individual. Addressing addiction as a disease does not remove the responsibility of 
the individual, which is the argument frequently used to resist recognizing and treating addiction as an illness. Rather it highlights the personal responsibility of the addicted person to seek and adhere to drug treatment and that of society to ensure that such treatment is available and based on scientific evidence. Only a small percentage of those requiring treatment for drug addiction seek help voluntarily; in light of this, the criminal justice system provides a unique opportunity to intervene and disrupt the cycle of drug use and crime in a cost-effective manner.

\section{Acknowledgements}

Funding/Support: This article was written by staff from the National Institute on Drug Abuse and there was no external funding for this work.

\section{References}

1. Glaze, LE.; Bonczar, TP. Probation and Parole in the United States, 2005. Washington, DC: Office of Justice Programs, Bureau of Justice Statistics; 2006. Dept of Justice publication NCJ 215091

2. Jensen EL, Gerber J, Mosher C. Social consequences of the War on Drugs: the legacy of failed policy. Criminal Justice Policy Review 2004;15(1):100-121.

3. Karberg, JC.; James, DJ. Substance Dependence, Abuse, and Treatment of Jail Inmates, 2002. Washington, DC: Office of Justice Programs, Bureau of Justice Statistics; 2005. Dept of Justice publication NCJ 209588

4. Mumola, CJ.; Karberg, JC. Drug Use and Dependence, State and Federal Prisoners, 2004. Washington, DC: Office of Justice Programs, Bureau of Justice Statistics; 2006. Dept of Justice publication NCJ 213530

5. Weinbaum CM, Sabin KM, Santibanez SS. Hepatitis B, hepatitis C, and HIV in correctional populations: a review of epidemiology and prevention. AIDS 2005;19(suppl 3):S41-S46. [PubMed: 16251827]

6. Abram KM, Teplin LA. Co-occurring disorders among mentally ill jail detainees: implications for public policy. Am Psychol 1991;46(10):1036-1045. [PubMed: 1746771]

7. Chandler RK, Peters RH, Field G, Juliano-Bult D. Challenges in implementing evidence-based treatment practices for co-occurring disorders in the criminal justice system. Behav Sci Law 2004;22 (4):431-448. [PubMed: 15282833]

8. Knight, K.; Farabee, D., editors. Treating Addicted Offenders: A Continuum of Effective Practices. Kingston, NJ: Civic Research Institute; 2004.

9. Langan, PA.; Levin, DJ. Recidivism of Prisoners Released in 1994. Washington, DC: Office of Justice Programs, Bureau of Justice Statistics; 2002. Dept of Justice publication NCJ 193427

10. Simpler AH, Langhinrichsen-Rohling J. Substance use in prison: how much occurs and is it associated with psychopathology? Addict Res Theory 2005;13(5):503-511.

11. Field, G. Continuity of offender treatment: from the institution to the community. In: Knight, K.; Farabee, D., editors. Treating Addicted Offenders: A Continuum of Effective Practices. Kingston, NJ: Civic Research Institute; 2004. p. 33-1-33-9.

12. Shivy VA, Wu JJ, Moon AE, Mann SC, Holland JG, Eacho C. Ex-offenders reentering the workforce. J Couns Psychol 2007;54(4):466-473.

13. Volkow ND, Wang GJ, Telang F, et al. Cocaine cues and dopamine in dorsal striatum: mechanism of craving in cocaine addiction. J Neurosci 2006;26(24):6583-6588. [PubMed: 16775146]

14. Nestler EJ. Review: transcriptional mechanisms of addiction: role of Delta FosB. Philos Trans R Soc Lond B Biol Sci 2008;363(1507):3245-3255. [PubMed: 18640924]

15. Grimm JW, Hope BT, Wise RA, Shaham Y. Neuroadaptation: incubation of cocaine craving after withdrawal. Nature 2001;412(6843):141-142. [PubMed: 11449260]

16. Inciardi JA, Martin SS, Butzin CA, Hooper RM, Harrison LD. An effective model of prison-based treatment for drug-involved offenders. J Drug Issues 1997;27(2):261-278.

17. Pearson FS, Lipton DS. A meta-analytic review of the effectiveness of corrections-based treatments for drug abuse. Prison J 1999;79(4):384-410. 
18. Leukefeld, CG.; Tims, F.; Farabee, D., editors. Treatment of Drug Offenders: Policies and Issues. New York, NY: Springer; 2002.

19. Wormith JS, Althouse R, Simpson M, Reitzel LR, Fagan TJ, Morgan RD. The rehabilitation and reintegration of offenders - the current landscape and some future directions for correctional psychology. Crim Justice Behav 2007;34(7):879-892.

20. Prendergast ML, Podus D, Chang E, Urada D. The effectiveness of drug abuse treatment: a metaanalysis of comparison group studies. Drug Alcohol Depend 2002;67(1):53-72. [PubMed: 12062779]

21. De Leon, G. Therapeutic communities: is there an essential model?. In: De Leon, G., editor. Community as Method: Therapeutic Communities for Special Populations and Special Settings. Westport, CT: Praeger; 1997. p. 3-18.

22. Volkow ND, Li TK. Drugs and alcohol: treating and preventing abuse, addiction and their medical consequences. Pharmacol Ther 2005;108(1):3-17. [PubMed: 16098597]

23. Johnson BA, Rosenthal N, Capece JA, et al. Topiramate for Alcoholism Advisory Board; Topiramate for Alcoholism Study Group. Topiramate for treating alcohol dependence: a randomized controlled trial. JAMA 2007;298(14):1641-1651. [PubMed: 17925516]

24. Cropsey KL, Villalobos GC, St Clair CL. Pharmacotherapy treatment in substance-dependent correctional populations: a review. Subst Use Misuse 2005;40(13-14):1983-1999. [PubMed: 16282089]

25. Humphreys K, Wing S, McCarty D, et al. Self-help organizations for alcohol and drug problems: toward evidence-based practice and policy. J Subst Abuse Treat 2004;26(3):151-158. [PubMed: 15063905]

26. Lurigio AJ. Drug treatment availability and effectiveness-studies of the general and criminal justice populations. Crim Justice Behav 2000;27(4):495-528.

27. Mitchell O, Wilson DB, MacKenzie DL. Does incarceration-based drug treatment reduce recidivism? a meta-analytic synthesis of the research. J Exp Criminol 2007;3(4):353-375.

28. Peters RH, Murrin MR. Effectiveness of treatment-based drug courts in reducing recidivism. Crim Justice Behav 2000;27(1):72-96.

29. Butzin CA, O’Connell DJ, Martin SS, Inciardi JA. Effect of drug treatment during work release on new arrests and incarcerations. J Crim Justice 2006;34(5):557-565.

30. Martin SS, Butzin CA, Saum CA, Inciardi JA. Three-year outcomes of therapeutic community treatment for drug-involved offenders in Delaware: from prison to work release to aftercare. Prison J 1999;79(3):294-320.

31. Gordon MS, Kinlock TW, Schwartz RP, O'Grady KE. A randomized clinical trial of methadone maintenance for prisoners: findings at 6 months post-release. Addiction 2008;103(8):1333-1342. [PubMed: 18855822]

32. Kinlock TW, Gordon MS, Schwartz RP, O'Grady KE. A study of methadone maintenance for male prisoners. Crim Justice Behav 2008;35(1):34-47. [PubMed: 18612373]

33. Kinlock TW, Gordon MS, Schwartz RP, O' Grady K, Fitzgerald TT, Wilson M. A randomized clinical trial of methadone maintenance for prisoners: results at 1-month post-release. Drug Alcohol Depend 2007;91(2-3):220-227. [PubMed: 17628351]

34. Rich JD, Boutwell AE, Shield DC, et al. Attitudes and practices regarding the use of methadone in US state and federal prisons. J Urban Health 2005;82(3):411-419. [PubMed: 15917502]

35. McCollister KE, French MT, Prendergast ML, Hall E, Sacks S. Long-term cost effectiveness of addiction treatment for criminal offenders. Justice Q 2004;21(3):659-679.

36. Stephan, JJ. State Prison Expenditures, 2001. Washington, DC: Office of Justice Programs, Bureau of Justice Statistics; 2004. Dept of Justice publication NCJ 202949

37. Rich JD, McKenzie M, Shield DC, et al. Linkage with methadone treatment upon release from incarceration: a promising opportunity. J Addict Dis 2005;24(3):49-59. [PubMed: 16186082]

38. Logan TK, Hoyt WH, McCollister KE, French MT, Leukefeld C, Minton L. Economic evaluation of drug court: methodology, results, and policy implications. Eval Program Plann 2004;27(4):381-396.

39. Daley M, Love CT, Shepard DS, Petersen CB, White KL, Hall FB. Cost-effectiveness of Connecticut's in-prison substance abuse treatment. J Offender Rehabil 2004;39(3):69-92. 
40. Flynn PM, Kristiansen PL, Porto JV, Hubbard RL. Costs and benefits of treatment for cocaine addiction in DATOS. Drug Alcohol Depend 1999;57(2):167-174. [PubMed: 10617100]

41. Zarkin GA, Dunlap LJ, Hicks KA, Mamo D. Benefits and costs of methadone treatment: results from a lifetime simulation model. Health Econ 2005;14(11):1133-1150. [PubMed: 15880389]

42. Taxman FS, Perdoni ML, Harrison LD. Drug treatment services for adult offenders: the state of the state. J Subst Abuse Treat 2007;32(3):239-254. [PubMed: 17383549]

43. Hammett TM, Roberts C, Kennedy S. Health-related issues in prisoner reentry. Crime Delinq 2001;47 (3):390-409.

44. Binswanger IA, Stern MF, Deyo RA, et al. Release from prison-a high risk of death for former inmates [published correction appears in N Engl J Med. 2007;356(5):536]. N Engl J Med 2007;356 (2):157-165. [PubMed: 17215533]

45. Boutwell AE, Allen SA, Rich JD. Opportunities to address the hepatitis C epidemic in the correctional setting. Clin Infect Dis 2005;40(suppl 5):S367-S372. [PubMed: 15768350]

46. Zaller N, Thurmond P, Rich JD. Limited spending: an analysis of correctional expenditures on antiretrovirals for HIV-infected prisoners. Public Health Rep 2007;122(1):49-54. [PubMed: 17236608]

47. Desai AA, Latta ET, Spaulding A, Rich JD, Flanigan TP. The importance of routine HIV testing in the incarcerated population: the Rhode Island experience. AIDS Educ Prev 2002;14(5 suppl B):4552. [PubMed: 12413192]

48. Sabin KM, Frey RL Jr, Horsley R, Greby SM. Characteristics and trends of newly identified HIV infections among incarcerated populations: CDC HIV voluntary counseling testing and referral system 1992-1998. J Urban Health 2001;78(2):241-255. [PubMed: 11419578]

49. Allen SA, Spaulding AC, Osei AM, Taylor LE, Cabral AM, Rich JD. Treatment of chronic hepatitis $\mathrm{C}$ in a state correctional facility. Ann Intern Med 2003;138(3):187-190. [PubMed: 12558357]

50. Vallabhaneni S, Macalino GE, Reinert SE, Schwartzapfel B, Wolf FA, Rich JD. Prisoners favour hepatitis C testing and treatment. Epidemiol Infect 2006;134(2):243-248. [PubMed: 16490126]

51. Rich JD, Holmes L, Salas C, et al. Successful linkage of medical care and community services for HIV-positive offenders being released from prison. J Urban Health 2001;78(2):279-289. [PubMed: 11419581]

52. Springer SA, Pesanti E, Hodges J, Macura T, Doros G, Altice FL. Effectiveness of antiretroviral therapy among HIV-infected prisoners: reincarceration and the lack of sustained benefit after release to the community. Clin Infect Dis 2004;38(12):1754-1760. [PubMed: 15227623]

53. Freudenberg N. Jails, prisons, and the health of urban populations: a review of the impact of the correctional system on community health. J Urban Health 2001;78(2):214-235. [PubMed: 11419576]

54. Uhl GR, Grow RW. The burden of complex genetics in brain disorders. Arch Gen Psychiatry 2004;61 (3):223-229. [PubMed: 14993109]

55. Volkow N, Li TK. The neuroscience of addiction. Nat Neurosci 2005;8(11):1429-1430. [PubMed: 16251981]

56. Uhl GR. Molecular genetic underpinnings of human substance abuse vulnerability: likely contributions to understanding addiction as a mnemonic process. Neuropharmacology 2004;47(suppl 1):140-147. [PubMed: 15464133]

57. Volkow ND, Fowler JS, Wang GJ. The addicted human brain: insights from imaging studies. J Clin Invest 2003;111(10):1444-1451. [PubMed: 12750391]

58. Koob GF, Le Moal M. Plasticity of reward neurocircuitry and the "dark side" of drug addiction. Nat Neurosci 2005;8(11):1442-1444. [PubMed: 16251985]

59. Naqvi NH, Rudrauf D, Damasio H, Bechara A. Damage to the insula disrupts addiction to cigarette smoking. Science 2007;315(5811):531-534. [PubMed: 17255515]

60. Hester R, Garavan H. Executive dysfunction in cocaine addiction: evidence for discordant frontal, cingulate, and cerebellar activity. J Neurosci 2004;24(49):11017-11022. [PubMed: 15590917]

61. Fellows LK. The role of orbitofrontal cortex in decision making: a component process account. Ann N Y Acad Sci 2007;1121:421-430. [PubMed: 17846161]

62. Kalivas PW, Volkow ND. The neural basis of addiction: a pathology of motivation and choice. Am J Psychiatry 2005;162(8):1403-1413. [PubMed: 16055761] 
63. Everitt BJ, Robbins TW. Neural systems of reinforcement for drug addiction: from actions to habits to compulsion. Nat Neurosci 2005;8(11):1481-1489. [PubMed: 16251991]

64. Gray MA, Critchley HD. Interoceptive basis to craving. Neuron 2007;54(2):183-186. [PubMed: 17442239]

65. Kosten TR, Markou A, Koob GF. Depression and stimulant dependence: neurobiology and pharmacotherapy. J Nerv Ment Dis 1998;186(12):737-745. [PubMed: 9865811]

66. Koob GF, Le Moal M. Drug abuse: hedonic homeostatic dysregulation. Science 1997;278(5335):52_ 58. [PubMed: 9311926]

67. Winstanley CA. The orbitofrontal cortex, impulsivity, and addiction: probing orbitofrontal dysfunction at the neural, neurochemical, and molecular level. Ann N Y Acad Sci 2007;1121:639655. [PubMed: 17846162]

68. Yücel M, Lubman DI, Solowij N, Brewer WJ. Understanding drug addiction: a neuropsychological perspective. Aust N Z J Psychiatry 2007;41(12):957-968. [PubMed: 17999268]

69. Bickel WK, Miller ML, Yi R, Kowal BP, Lindquist DM, Pitcock JA. Behavioral and neuroeconomics of drug addiction: competing neural systems and temporal discounting processes. Drug Alcohol Depend 2007;90(suppl 1):S85-S91. [PubMed: 17101239]

70. Madden GJ, Petry NM, Badger GJ, Bickel WK. Impulsive and self-control choices in opioiddependent patients and non-drug-using control participants: drug and monetary rewards. Exp Clin Psychopharmacol 1997;5(3):256-262. [PubMed: 9260073]

71. Shaham Y, Hope BT. The role of neuroadaptations in relapse to drug seeking. Nat Neurosci 2005;8 (11):1437-1439. [PubMed: 16251983]

72. Baler RD, Volkow ND. Drug addiction: the neurobiology of disrupted self-control. Trends Mol Med 2006;12(12):559-566. [PubMed: 17070107]

73. Ersche KD, Sahakian BJ. The neuropsychology of amphetamine and opiate dependence: implications for treatment. Neuropsychol Rev 2007;17(3):317-336. [PubMed: 17690986]

74. Kosten TR. Addiction as a brain disease. Am J Psychiatry 1998;155(6):711-713. [PubMed: 9619141]

75. Fletcher, BW.; Chandler, RK. Principles of Drug Abuse Treatment for Criminal Justice Populations. Washington, DC: National Institute on Drug Abuse; 2006. NIH publication 06-5316

76. Wilson DB, Bouffard LA, Mackenzie DL. A quantitative review of structured, group-oriented, cognitive-behavioral programs for offenders. Crim Justice Behav 2005;32(2):172-204.

77. Gostin LO. Biomedical research involving prisoners: ethical values and legal regulation. JAMA 2007;297(7):737-740. [PubMed: 17312293]

78. Wexler HK, Fletcher BW. National Criminal Justice Drug Abuse Treatment Studies (CJ-DATS) overview. Prison J 2007;87(1):9-24.

79. Comer SD, Collins ED, Kleber HD, Nuwayser ES, Kerrigan JH, Fischman MW. Depot naltrexone: long-lasting antagonism of the effects of heroin in humans. Psychopharmacology (Berl) 2002;159 (4):351-360. [PubMed: 11823887]

80. Comer SD, Sullivan MA, Yu E, et al. Injectable, sustained-release naltrexone for the treatment of opioid dependence: a randomized, placebo-controlled trial. Arch Gen Psychiatry 2006;63(2):210 218. [PubMed: 16461865]

81. Dackis C, O'Brien C. Neurobiology of addiction: treatment and public policy ramifications. Nat Neurosci 2005;8(11):1431-1436. [PubMed: 16251982] 


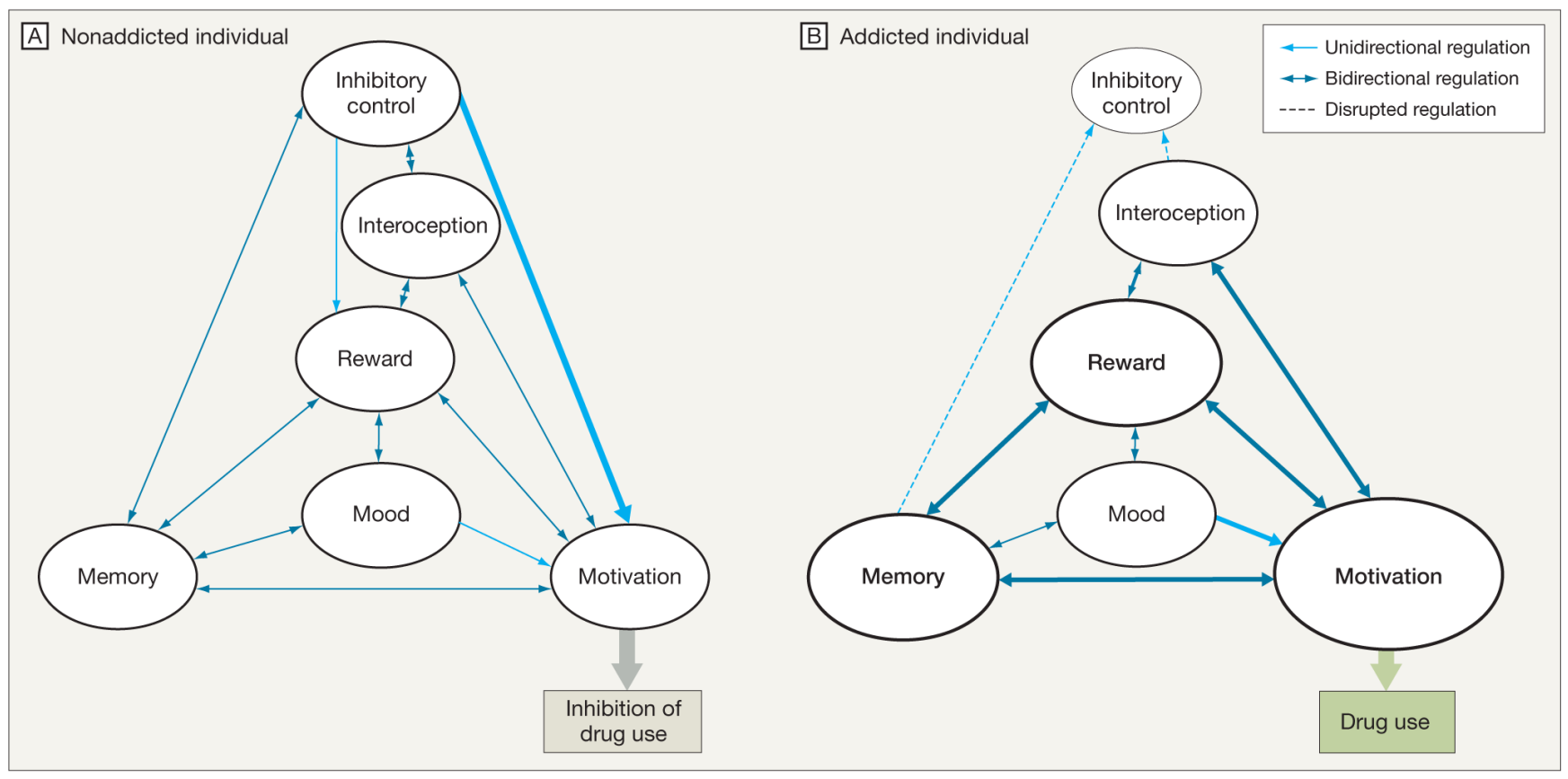

Figure. Proposed Network of Brain Circuits Involved With Addiction 57

Circuits work together and change with experience. Each is linked to an important concept: reward (saliency), motivation (drive), memory (learning associations), inhibitory control (conflict resolution), mood (well-being), ${ }^{58}$ and interoception (internal awareness) ${ }^{59}$ Size of circuit ovals indicates influence in determining behavioral outcomes. Thicker line weights indicate greater influence on regulation of the circuit. A, In a nonaddicted person the decision to consume a drug (same process pertains for natural rewards) is a function of the balance between the expected pleasure (based on past experience or memory), alternative stimuli (this includes internal states such as mood and interoception but also alternative external rewards), and potential negative outcomes that oppose the motivation to take the drug (inhibitory control exerted by prefrontal cortex) and stop the drug use. B, During addiction, the enhanced value of the drug in the reward, motivation, and memory circuits overcomes the inhibitory control exerted by the prefrontal cortex, thereby favoring a positive feedback loop initiated by the consumption of the drug and perpetuated by enhanced activation of the motivation/drive and memory circuits. Decreased sensitivity to rewards also raises the hedonic threshold, disrupting mood and increasing the saliency values of drugs and behaviors temporarily associated with relief from the dysphoria. Learning and conditioning result in an enhanced interoceptive awareness of discomfort and the associated desire for the drug (craving). Absence of lines from inhibitory control circuit to reward and motivation circuits indicates loss of regulation. 
Table 1

Inmate Drug Use, Abuse/Dependence, and Treatment

No. $(\%)$

\begin{tabular}{|c|c|c|c|c|}
\hline \multirow[b]{3}{*}{ Inmate Type } & \multicolumn{4}{|c|}{ No. $(\%)$} \\
\hline & \multicolumn{2}{|c|}{ Drug Use } & \multicolumn{2}{|c|}{ Drug Abuse or Dependence } \\
\hline & At Time of Offense & $\begin{array}{r}\text { In Month Prior to } \\
\text { Offense }\end{array}$ & Met Criteria & $\begin{array}{l}\text { Received Treatment } \\
\text { While Incarcerated }\end{array}$ \\
\hline Local jail inmates $a, b$ & $128030(29)$ & $242720(55)$ & $245830(55)$ & $16520(7)$ \\
\hline State inmates ${ }^{c}$ & $393610(32)$ & $686670(56)$ & $642500(53)$ & $95090(15)$ \\
\hline Federal inmates ${ }^{c}$ & $34140(26)$ & $64910(50)$ & $57200(46)$ & $9950(17)$ \\
\hline
\end{tabular}

${ }^{a}$ Convicted jail inmates only. If all jail inmates are included, 50\% were under the influence of drugs at the time of the offense, and about two-thirds were regular users.

${ }^{b}$ Weighted estimates derived from the US Bureau of Justice Statistics Survey of Inmates in Local Jails, $2002 .{ }^{3}$ A stratified sample of 6982 inmates were interviewed (9.9\% refusal rate) in 417 jails (of 465 selected). Survey methodology is described in Karberg and James. ${ }^{3}$

${ }^{c}$ Weighted estimates derived from the US Bureau of Justice Statistics Survey of Inmates in State and Federal Correctional Facilities, $2004 .{ }^{4}$ In the state prison sample, a total of 14499 inmates were interviewed (10.2\% refusal rate) in 287 state prisons (of 301 selected). In the federal prison sample, a total of 3686 inmates were interviewed (13.3\% refusal rate) in 39 federal prisons (of 40 selected). Survey methodology is described in Mumola and Karberg. 4 


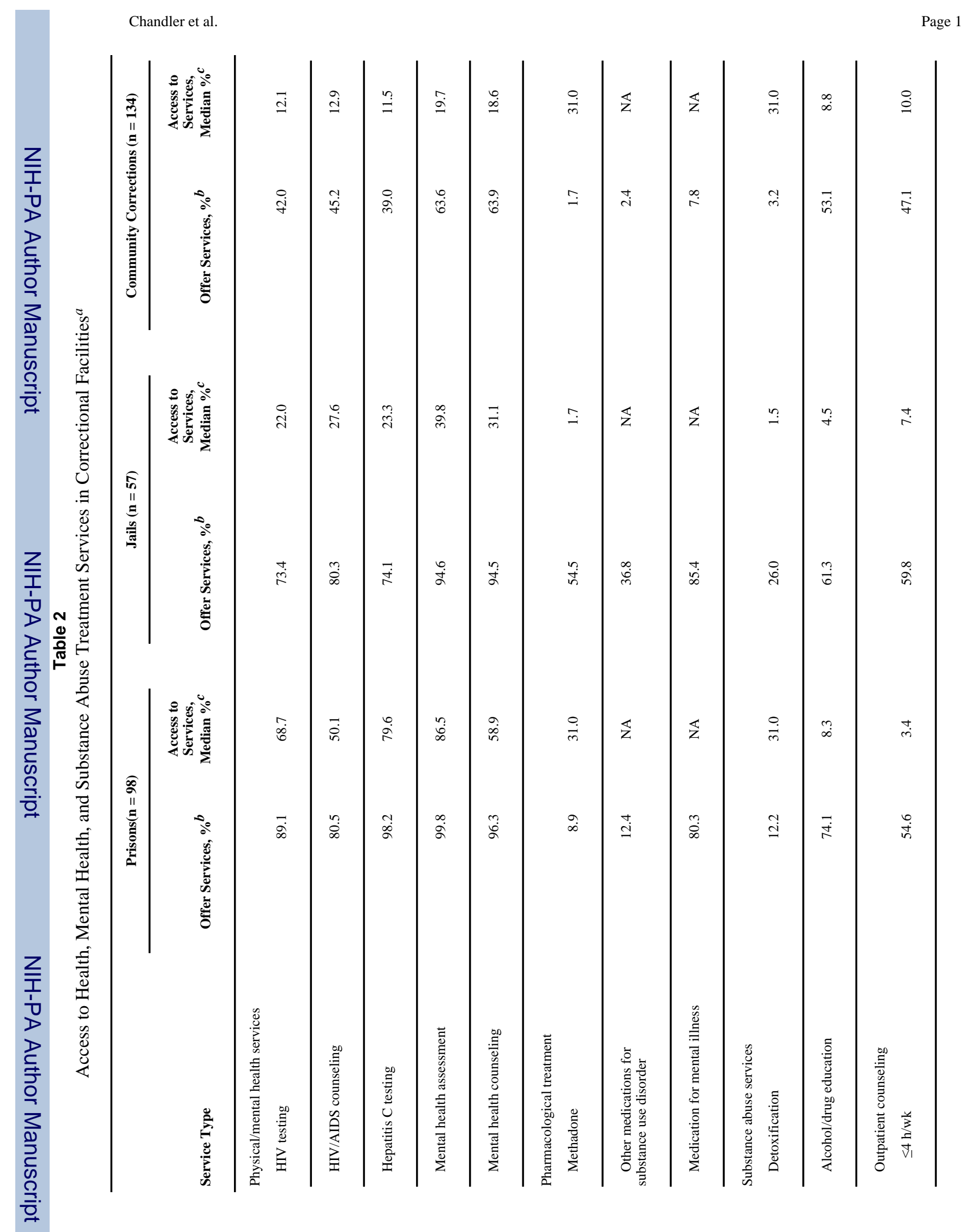




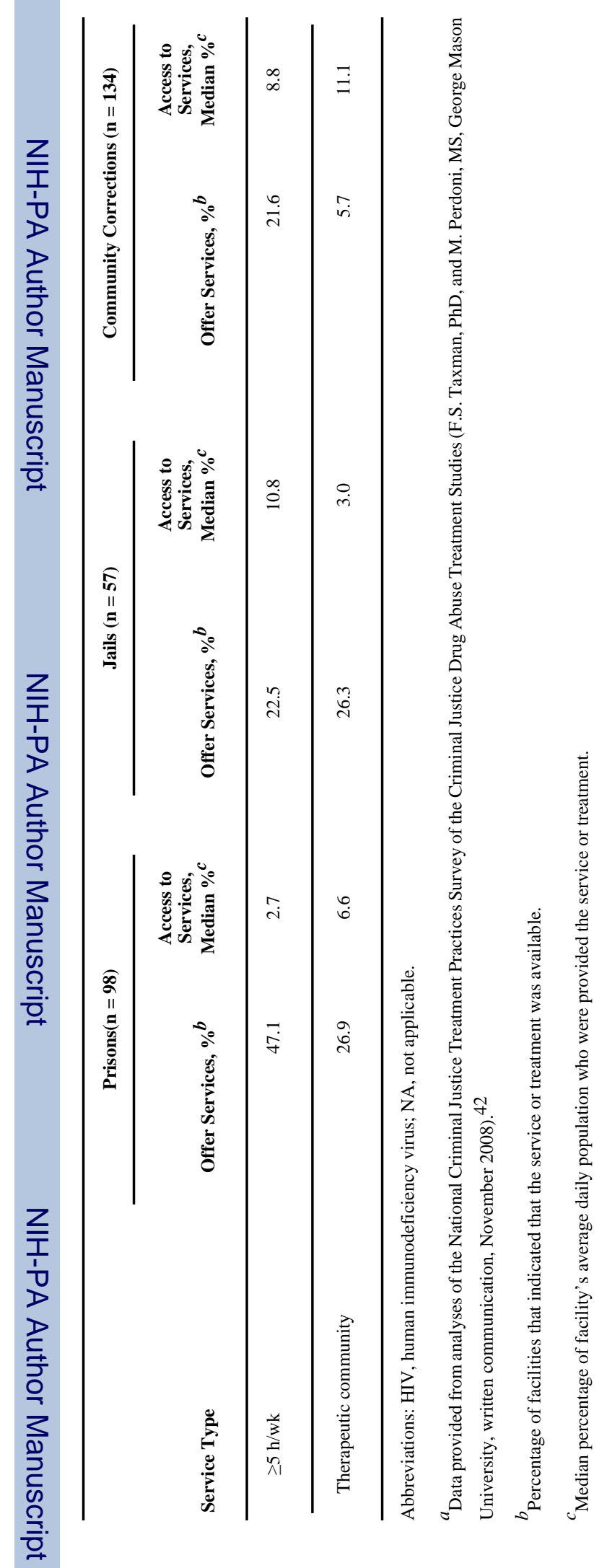


Table 3

Intervention Opportunities in Criminal Justice Systems

\begin{tabular}{|c|c|c|c|}
\hline Stage & Offender Event & Participants & Intervention Opportunities \\
\hline Entry & Arrest & $\begin{array}{l}\text { Crime victim } \\
\text { Police } \\
\text { FBI }\end{array}$ & Screening or referral \\
\hline Prosecution & $\begin{array}{l}\text { Court } \\
\text { Pretrial release } \\
\text { Jail }\end{array}$ & $\begin{array}{l}\text { Crime victim } \\
\text { Police } \\
\text { FBI } \\
\text { Judge }\end{array}$ & $\begin{array}{l}\text { Diversion programs } \\
\text { Drug courts } \\
\text { Community-based treatment } \\
\text { TASC }^{a}\end{array}$ \\
\hline Adjudication & Trial & $\begin{array}{l}\text { Prosecutor } \\
\text { Defense attorney } \\
\text { Defendant } \\
\text { Jury } \\
\text { Judge }\end{array}$ & NA \\
\hline Sentencing & $\begin{array}{l}\text { Fines } \\
\text { Community supervision } \\
\text { Incarceration }\end{array}$ & $\begin{array}{l}\text { Jury } \\
\text { Judge }\end{array}$ & $\begin{array}{l}\text { Drug court } \\
\text { Terms of incarceration } \\
\text { Release conditions }\end{array}$ \\
\hline Corrections & $\begin{array}{l}\text { Probation } \\
\text { Jail } \\
\text { Prison }\end{array}$ & $\begin{array}{l}\text { Probation officers } \\
\text { Correctional personnel }\end{array}$ & $\begin{array}{l}\text { Screening and treatment for substance } \\
\text { use disorders } \\
\text { Screening and treatment for other mental } \\
\text { illnesses } \\
\text { Screening and treatment for other } \\
\text { medical disorders }\end{array}$ \\
\hline Community reentry & $\begin{array}{l}\text { Probation } \\
\text { Parole } \\
\text { Release }\end{array}$ & $\begin{array}{l}\text { Probation or parole officer } \\
\text { Family } \\
\text { Community-based providers }\end{array}$ & $\begin{array}{l}\text { Drug treatment } \\
\text { Aftercare } \\
\text { Housing } \\
\text { Employment } \\
\text { Mental health } \\
\text { Medical care } \\
\text { Halfway house } \\
\text { TASC }\end{array}$ \\
\hline
\end{tabular}

Abbreviations: FBI, Federal Bureau of Investigation; NA, not applicable; TASC, Treatment Accountability for Safer Communities.

${ }^{a}$ Interventions of the TASC organization are based on a case management model for integrating criminal justice and drug abuse treatment services. 